\title{
Osteoprotective Activity and Metabolite Fingerprint via UPLC/MS and GC/MS of Lepidium sativum in Ovariectomized Rats
}

\author{
Hossam M. Abdallah 1,2,*(D), Mohamed A. Farag 2,3, Mardi M. Algandaby ${ }^{4}$, \\ Mohammed Z. Nasrullah ${ }^{5}$ (D) Ashraf B. Abdel-Naim ${ }^{5}$, Basma G. Eid ${ }^{5}$, Martin K. Safo ${ }^{6}{ }^{(D)}$, \\ Abdulrahman E. Koshak ${ }^{1}$ (D) and Azizah M. Malebari ${ }^{7}$ \\ 1 Department of Natural Products and Alternative Medicine, Faculty of Pharmacy, King Abdulaziz University, \\ Jeddah 21589, Saudi Arabia; aekoshak@kau.edu.sa \\ 2 Department of Pharmacognosy, Faculty of Pharmacy, Cairo University, Cairo 11562, Egypt; \\ mohamed.farag@pharma.cu.edu.eg \\ 3 Department of Chemistry, School of Sciences \& Engineering, The American University in Cairo, \\ New Cairo 11835, Egypt \\ 4 Department of Biological Sciences, Faculty of Science, King Abdulaziz University, Jeddah 21589, Saudi \\ Arabia; malgandaby@kau.edu.sa \\ 5 Department of Pharmacology and Toxicology, Faculty of Pharmacy, King Abdulaziz University, Jeddah \\ 21589, Saudi Arabia; mnasrullah@kau.edu.sa (M.Z.N.); aaabdulalrahman1@kau.edu.sa (A.B.A.-N.); \\ beid@kau.edu.sa (B.G.E.) \\ 6 Department of Medicinal Chemistry, Institute for Structural Biology, Drug Discovery and Development, \\ School of Pharmacy, Virginia Commonwealth University, Richmond, VA 23298, USA; msafo@vcu.edu \\ 7 Department of Pharmaceutical Chemistry, College of Pharmacy, King Abdulaziz University, Jeddah 21589, \\ Saudi Arabia; amelibary@kau.edu.sa \\ * Correspondence: hmafifi@kau.edu.sa; Tel.: +966-544733110
}

Received: 12 June 2020; Accepted: 9 July 2020; Published: 13 July 2020

check for updates

\begin{abstract}
Lepidium sativum seeds are used traditionally to accelerate healing of bone fracture in addition to its culinary uses. This study aimed to characterize the osteoprotective effect of L. sativum in an ovariectomized rat model at two dose levels (50 and $100 \mathrm{mg} / \mathrm{kg}$ ) using $17 \beta$-estradiol as a positive reference standard. Moreover, a complete metabolite profile of L. sativum via UHPLC/PDA/ESI-MS, as well as headspace solid-phase microextraction (SPME)-GC/MS is presented. Results revealed that L. sativum extract exhibited significant anti-osteoporotic actions as evidenced by mitigating the decrease in relative bone weight concurrent with improved longitudinal and perpendicular femur compression strength. Further, the extract enhanced the serum bone formation biomarkers lactate dehydrogenase (LDH) activity and osteocalcin levels. The extract also inhibited exhaustion of superoxide dismutase (SOD) as well as glutathione peroxidase (GPx) activities and accumulation of lipid peroxides in bone tissues. This is in addition to ameliorating the rise in the markers of bone resorption carboxyterminal telopeptide, type I (CTXI) and tartrate-resistant acid phosphatase (TRAP) and modulating receptor activator of nuclear factor kappa-B ligand (RANKL)/ osteoprotegerin (OPG) expression. Metabolite characterization suggests that glucosinolates, lignans, coumarins, phenolic acids, and alkaloids mediate these anti-osteoporotic effects in a synergistic manner.
\end{abstract}

Keywords: osteoprotection; Lepidium sativum; anti-oxidation; phenolics; ovariectomized rats; LC-MS fingerprint 


\section{Introduction}

Osteoporosis is a bone disorder, which is a consequence of imbalance in the formation and resorption of bone tissues in favor of bone loss, with elevated fracture risk. In the last two decades, osteoporosis has become a major health problem affecting a huge worldwide population [1]. Osteoporosis is associated with different health conditions, due to estrogen hormone deficiency during menopause or the consumption of corticosteroids [2]. Additionally, aging, malabsorption of calcium, and immune-related factors can also cause osteoporosis [3]. The bone demineralization processes can lead to fractures, particularly of the vertebrae and hip joint. Several studies indicated that women over 45 years of age are the most vulnerable to femoral fractures [4]. The incidence and cost of these fractures are rising and pose a heavy health and economic burden on the society [5]. Current therapy suffers from various adverse effects; from gastrointestinal disturbances to cancer [6,7]. This necessitates the search for new effective and safe therapies. In this regard, natural products have been advanced as attractive candidates for osteoporosis treatment [3]. Different plant secondary metabolites impact bone remodeling, for example, isoflavonoids (daidzein, genistein, cajanin, and formononetin due to their estrogenic properties), lignans (secoisolariciresinol and matairesinol, which are converted by gut microflora to mammalian lignans, enterodiol and enterolactone that are estrogenic). Furthermore, flavonoids such as quercetin, kaempferol, or hesperidin and carotenoids have all shown preservation of bone mineral density following ovariectomy-induced bone loss in female rodents $[8,9]$.

Lepidium sativum L., commercially known as "Hab al Rashad", grows in Saudi Arabia in several areas, such as AL-Qaseem and the Eastern Province [10]. Traditionally, it is used in folk medicine for bone fractures in the Arabian Peninsula [11]. Phytochemically, the seeds are rich in alkaloids (dimeric imidazole alkaloids lepidine B, C, D, E, and F) [12], anthracene glycosides, saponins, proteins and amino acids, carbohydrates, S-glycosides (allyl, 2-phenethyl, and benzyl glucosinolates), and flavonoids [13]. Experimentally, it has been reported to exhibit potent antihypertensive, hypoglycemic, and antioxidant activities [14]. In addition, it has been shown that the seeds are able to accelerate healing of the bone in glucocorticoid-induced osteoporosis in rats [2,15]. Moreover, it was able to accelerate healing of artificial fractures in the midshaft of the left femur of rabbits $[11,16]$. However, its anti-osteoporotic effects in ovariectomized rats and the possible underlying mechanisms have not been elucidated yet. Further, there is scarcity of data regarding a complete profiling of their active constituents and their possible role in bone healing. This study aimed to evaluate the osteoprotective effects of L. sativum seed extract in ovariectomized rats and characterize the metabolite composition of the extract by large-scale chemical profiling using UHPLC/PDA/ESI-MS and GC/MS.

\section{Material and Methods}

\subsection{Plant Material}

Lepidium sativum L. seeds (Hab el-Rashad) (Brassicaceae) were purchased from a local market in Jeddah and were identified by Dr. Faraj Alghamdi, Associate Professor of Plant Taxonomy, Biological Science Department, Faculty of Science, King Abdulaziz University. A specimen was kept at the Herbarium of the Faculty of Pharmacy, King Abdulaziz University (LS-1040).

\subsection{Extraction of Plant Material}

One kilogram of $L$. sativum seeds was grounded to a fine powder and extracted at room temperature with methanol $(3 \times 1 \mathrm{~L})$ till exhaustion. The extracts were refrigerated for future biological examination after evaporation under low pressure. 


\subsection{Biological Study}

\subsubsection{Determination of Oral Lethal Dose $50\left(\mathrm{LD}_{50}\right)$}

$\mathrm{LD}_{50}$ was determined in a separate experiment. A limiting dose of $2000 \mathrm{mg} / \mathrm{kg}$ of L. sativum methanol extract was tried in three female rats and observed for $24 \mathrm{~h}$. As no mortality was observed, the same procedure was repeated using additional three female rats; guided by OECD (Organization for Economic Co-operation and Development) guideline no. 423 [17].

\subsubsection{Animals and Animal Treatment}

Forty-five female Wistar rats weighing 190-220 g, from the Animal Facility, King Abdulaziz, University, Jeddah, Saudi Arabia were used in the study. They were maintained on a 12-h light-dark cycle and at an ambient temperature of $22 \pm 2{ }^{\circ} \mathrm{C}$. Protocols were approved by The Unit of Research Ethics, Faculty of Pharmacy, King Abdulaziz University, Saudi Arabia (PH-118-40). Animals were separated into five groups ( 9 each) randomly. Animals in group 1 were controls (sham) and were subjected to bilateral laparotomy only, without removing the ovaries. Animals in groups 2, 3, 4, and 5 were subjected to bilateral ovariectomy. All animals were left for 2 weeks to recover from surgery. Rats in group 1 (control) and group 2 were given a daily oral gavage of distilled water $(10 \mathrm{~mL} / \mathrm{kg})$. Groups 3 and 4 were given an oral gavage of L. sativum extract suspended in distilled water at a dose of 50 and $100 \mathrm{mg} / \mathrm{kg}$, respectively. A pilot study was performed to validate the chosen doses, which were also concurrent with the literature $[18,19]$. Animals in group 5 (positive drug control) were given $17 \beta$-estradiol (E2) dissolved in corn oil ( $25 \mathrm{mcg} / \mathrm{kg} /$ day, s.c.) [20,21] for a period of 12 weeks. Individual body weights were recorded at the end of the experiment. Light ether anesthetic was used for collection of blood from the retro-orbital plexus. Blood was left for coagulation (15 min), then centrifuged (2000X $g$ for $15 \mathrm{~min}$ ) and sera were collected and kept at $-80^{\circ} \mathrm{C}$. Then, animals were sacrificed under light ether anesthesia by decapitation. Bones of three rats from each group were used for compression strength assessment. For the remaining six rats in each group, right femurs were quickly dissected out, cleaned of soft tissue, weighed, and stored for biomechanical analysis at $-80{ }^{\circ} \mathrm{C}$. After dissection and cleaning of the left femurs, they were placed in $10 \%$ formalin for future histopathological examination.

\subsubsection{Determination of Relative Weights and Compression Strength}

Both femurs from each rat $(n=3)$ were completely separated and weighed. The relative bone weights were calculated as follows: wet femur weight/body weight and expressed multiplied by 1000 . Femur hardness was determined by a hardness tester (Erweka GmbH, Heusen-stamm, Germany) [22]. Femurs were placed longitudinally $(n=3)$ and perpendicularly $(n=3)$ to the force direction momentarily in the clamp assembly of the tester, and the minimal force causing bone shaft fracture was determined.

\subsubsection{Histological Examination}

Ten percent neutral buffered formalin was used for fixing the excised femurs followed by dehydration in ethanol, xylene clearing, and embedding in paraffin. On glass slides, cross vertical sections $(5 \mu \mathrm{m})$ of bone tissues were mounted. Hematoxylin and eosin (H\&E), Masson trichrome, and alizarin red stains were applied after dewaxing, and rehydration with distilled water. The samples were examined in a blinded fashion by an expert pathologist. Bone lesions were given scores as follows: Nil, -; Mild, +; Moderate, ++; Severe, +++.

\subsubsection{Assessment of Serum Markers of Bone Metabolism}

Serum alkaline phosphatase (ALP) activities and osteocalcin levels were determined using rat ELISA kits (Enzyme-Linked Immunosorbent Assay) (Wuhan USCN Life Science, Wuhan, China). A rat ELISA kit (Biomatik, Inc., Ontario, Canada) was used to assay collagen cross-linking carboxyterminal 
telopeptide, type I (CTXI). Another rat ELISA Kit (MyBioSource, San Diego, CA, USA) was employed for tartrate-resistant acid phosphatase (TRAP) determination.

\subsubsection{Preparation of Bone Homogenate}

Bones were homogenized (10\% of w/v in ice-cooled $0.1 \mathrm{M}$ phosphate buffer, $\mathrm{pH} 7.4)$ using a polytron homogenizer. This was followed by centrifugation for $20 \mathrm{~min}$ at $4{ }^{\circ} \mathrm{C}$ and $10,000 \times g$. Oxidative status markers and protein concentration were determined from the supernatant.

\subsubsection{Bone Tissue Oxidative Status Assessment}

Oxidative status was assessed from tissues of the distal epiphysis of the femur. Commercially available kits (Biodiagnostic, Giza, Egypt) were used to determine malondialdehyde (MDA), superoxide dismutase (SOD), and glutathione peroxidase (GPx) activities. Data were normalized to protein content as determined by BCA (bicinchoninic acid) protein assay kit (Sigma-Aldrich, St. Louis, MO, USA).

\subsubsection{RANKL and OPG Assessment via Quantitative Real-Time Polymerase Chain Reaction (PCR)}

Bone tissues of the distal epiphysis of the femur were homogenized in an ultrasonic probe. A nucleic acid extraction kit (NucleoSpin ${ }^{\circledR}$, Macherey-Nagel GmbH \& Co. KG, Duerin, Germany) was used for RNA extraction. A dual-wavelength spectrophotometer (Beckman, Spectrophotometer, USA) was utilized for determination of RNA purity (A260/A280 ratio) and concentration. Reverse transcription and real-time PCR was undertaken using SensiFAST ${ }^{\text {TM }}$ SYBR ${ }^{\circledR}$ Hi-ROX One-Step Kit; cat. no.: BIO-73005 (Bioline, a Meridian Bioscience company, London, UK). PCR amplification reactions were then performed using the following primers purchased from Qiagen, Valencia, CA, USA: tumor necrosis factor receptor superfamily, member 11b (Tnfsf11), also named as osteoprotegerin (OPG) (QT00195125); tumor necrosis factor (ligand) superfamily, member 11 (Tnfrsf11b), also named as receptor activator of nuclear factor kappa-B ligand (RANKL) (QT00177170); and the housekeeping (reference) gene (GAPDH) (QT00199633) using StepOne Real-Time PCR System (Applied Biosystems, Foster city, CA, USA). The ratio of target gene to GAPDH, with respect to control rats was calculated by the $\triangle \triangle C T$ technique and ratio to control values were used to give the results.

\subsubsection{Statistical Analysis}

Data are represented as mean \pm SD. Multiple comparisons were performed using one-way analysis of variance (ANOVA) followed by Tukey post hoc test. All analyses were performed using IBM SPSS ${ }^{\circledR}$ ver. 25 (SPSS Inc., Chicago, IL, USA). Differences were considered significant at $p<0.05$.

\subsection{Metabolites Characterization of L. sativum Seed Extract}

\subsubsection{Extraction and Preparation of Samples for UHPLC/PDA/ESI-MS}

L. sativum seeds were ground with liquid nitrogen and sixteen $\mathrm{mg}$ of the ground material was homogenized using a Turrax mixer with methanol $(1.5 \mathrm{~mL})$ containing umbelliferone as an internal standard $(10 \mu \mathrm{g} / \mathrm{mL})$. Prepared extracts were purified from plant debris by centrifugation for half an hour at $3000 \times g$. An aliquot of $3 \mu \mathrm{L}$ of the supernatant was employed in the UHPLC/PDA/ESI-ion trap MS analysis according to the chromatographic conditions and mass spectrometer parameters described previously [23,24].

\subsubsection{Analysis of UHPLC-Orbitrap-HRMS}

An Orbitrap Elite mass spectrometer (Thermo Fisher Scientific, Darmstadt, Germany) was used for high-resolution ESI-MS in positive and negative modes, and collision-induced dissociation (CID) spectra and conditioning of UHPLC as described previously [25]. Mass spectra, V-VIS spectra $(220-600 \mathrm{~nm})$, phytochemical dictionary of natural products database (CRC) literature was used to characterize metabolites. 


\subsubsection{Volatiles Analysis of L. sativum Seeds via Headspace GC/MS}

The protocol by Farag et al. (2017b) was used for HS-SPME volatile analysis [26]. Retention indices (RI) were compared to relative to n-alkanes (C6-C20), mass matching to NIST, WILEY library database and with standards for identification of volatile components. Before matching mass spectra, AMDIS software (www.amdis.net) was used for peak deconvolution.

\section{Results and Discussion}

Osteoporosis is caused by different risk factors, including estrogen hormone deficiency after menopause, consumption of corticosteroids, aging, malabsorption of calcium, or immune-related factors. Treatment of osteoporosis by synthetic drugs involves a wide range of side effects. Natural treatments may constitute a healthier and safer treatment option. Herbal remedies have been exploited worldwide due to their efficacy, relative safety, and low-cost. Several plant extracts and natural compounds have been examined for their potential role in protecting against osteoporosis. Many natural active constituents have demonstrated positive effects in bone formation in osteoporosis: including flavonoids (icariin, naringin, ugonin $\mathrm{K}$, genistein, puerarin, quercetin, and rutin), phenyl ethanoids (echinacoside), phenolic acids (salvianolic acid B), diterpenoid (kirenol), sesquiterpene (costunolide), stilbene (kobophenol A), and coumarins (imperatorin and bergapten) [3]. This study was designed to explore the mechanism of osteoprotective activity of L. sativum seed extract in ovariectomized rats. Characterization of the extract's metabolite composition was assessed using large-scale chemical profiling using UHPLC/PDA/ESI-MS and GC/MS.

\subsection{Biological Study}

\subsubsection{Oral $\mathrm{LD}_{50}$ of L. sativum Extract}

Twenty-four hours after an oral dosing of $2000 \mathrm{mg} / \mathrm{kg}$ of L. sativum methanol extract to rats, no deaths were recorded in the three tested female animals. Further studies were carried out in three additional female animals using the same dose, which similarly resulted in no deaths in $24 \mathrm{~h}$.

L. sativum $\left(\mathrm{LD}_{50}>2000 \mathrm{mg} / \mathrm{kg}\right.$ ) is considered to be Category 5 based on the Acute Toxic Class Method reported in OECD guideline no. 423.

\subsubsection{Effect of L. sativum on Femur Relative Weight and Compression Strength}

To determine the effects of L. sativum on ovariectomy-induced osteoporosis, femur relative weights were determined. Compared with the control (sham) group, ovariectomy (c) resulted in an almost one-third decrease in bone relative weight. The observed osteoporosis induced by ovariectomy is consistent with many previous clinical and experimental reports $[27,28]$. However, treatment with L. sativum resulted in significant enhancement of bone relative weight by $18 \%$ and $35 \%$ respectively, as compared to the ovariectomized animals (OVX). It is noteworthy to report that $L$. sativum's effects were comparable to that of the estradiol group (Figure 1A). Further, the anti-osteoporotic activities of L. sativum extract are supported by previous reports highlighting its synergistic effects with alendronate against glucocorticoid-induced osteoporosis in rats [2]. To confirm these data, longitudinal and perpendicular femur bone strengths were assessed. Ovariectomy significantly decreased longitudinal and perpendicular compression strengths by $38 \%$ and $41 \%$ respectively, of the control value. A daily dose of $50 \mathrm{mg} / \mathrm{kg}$ of L. sativum enhanced the longitudinal and perpendicular strengths by $33 \%$ and $52 \%$, respectively. The higher dose $(100 \mathrm{mg} / \mathrm{kg})$ resulted in an improvement of both strengths by $49 \%$ and $62 \%$, respectively (Figure $1 B, C$ ). These observations suggest that L. sativum could significantly ameliorate bone-weakening. The observed bone-strengthening activity of L. sativum is in line with the clinical notion that the plant improved chronic periodontitis in osteoporotic postmenopausal women as indicated by radiography and clinical signs and symptoms [29]. 

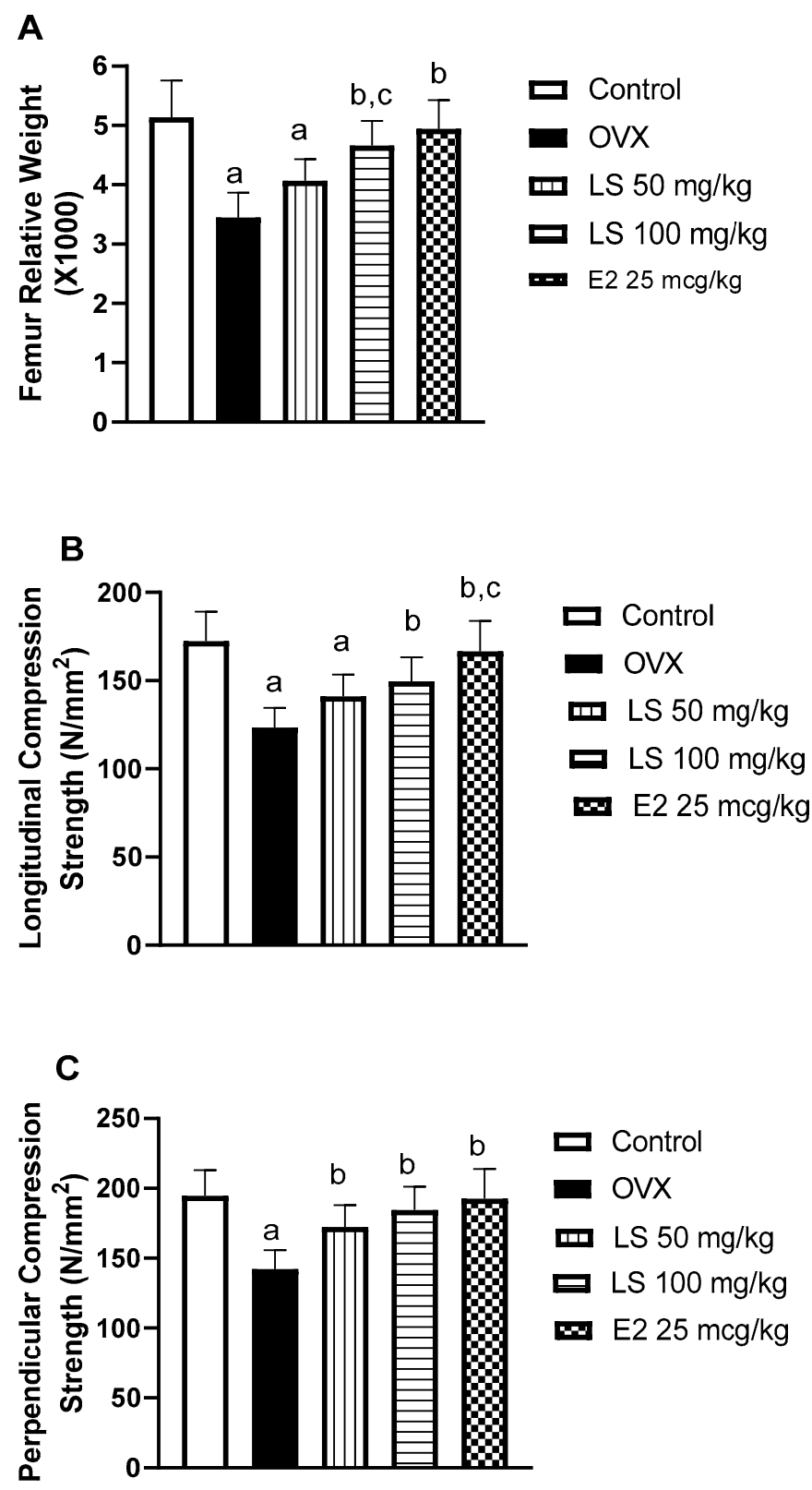

Figure 1. Effect of Lepidium sativum (LS) on femur relative weight and compression strength in ovariectomized rats. (A) Femur relative weight, (B) longitudinal force, (C) femur perpendicular force. Data are presented as Mean \pm Standard Deviation $(M \pm S D)$. (a) Significantly different from control at $p<0.05$. (b) Significantly different from ovariectomized animals (OVX) at $p<0.05$. (c) Significantly different from LS $50 \mathrm{mg} / \mathrm{kg}$ at $p<0.05$.

\subsubsection{Histological Examination of Femurs}

In addition to classical examination of sections stained with $H \& E$, femur sections were also stained with Masson trichrome and alizarin red stains to give better detection of collagen fibers and calcium-containing osteocytes. Control animals showed average periosteum, normal cortical thickness with regular dense lamellae, intact well-formed dense bony trabeculae with dense lamellae, and average intervening bone marrow. Moreover, Masson trichrome staining showed parallel regular arrangement of collagen fibers. Alizarin red stained-sections exhibited regular cortex and trabeculae (Figure 2A). Animals in the OVX group displayed a thin eroded cortex with large osteocytes in large lacunae, foci of calcified cartilage, thin eroded disconnected and hypo-mineralized bony trabeculae with osteoclastic activity. Masson trichrome-stained sections showed irregular arrangement of collagen fibers while 
alizarin red staining showed almost non-reactive cortex and trabeculae (Figure 2B). Treatment of ovariectomized animals with L. sativum (50 or $100 \mathrm{mg} / \mathrm{kg}$ ) showed relatively thin cortex with irregular dense lamellae and large osteocytes in large lacuna, well-formed relatively thin eroded bony trabeculae with regular and irregular dense lamellae, osteoblastic rimming with minimal osteoclastic activity, foci of calcified cartilage, regular arrangement of collagen fibers in cortex and trabeculae, and trabeculae almost non-reactive for alizarin red (Figure 2C,D). Animals in the positive control group treated with estradiol showed almost normal femur architecture (Figure 2E). Injury scoring in all treatment groups is shown in a tabular presentation (Figure $2 \mathrm{~F}$ ). The table indicates that ovariectomy resulted in obvious signs of osteoporosis that include thinning of the cortex and trabeculae, widening of bone marrow spaces, and a few fissures. Nevertheless, L. sativum in both doses (50 and $100 \mathrm{mg} / \mathrm{kg}$ ) ameliorated all these pathological effects that are comparable to that of estradiol (Figure 2F).

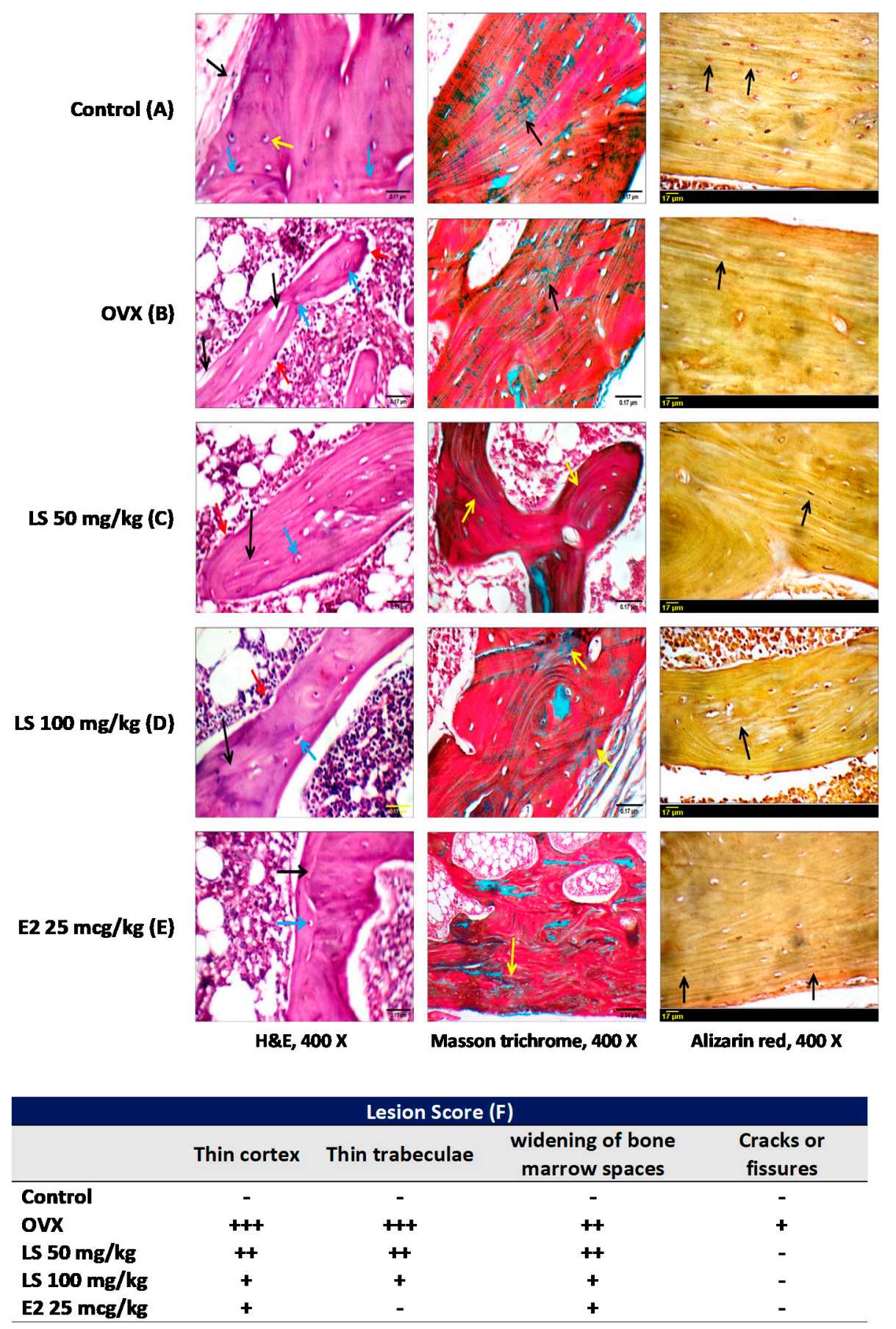


Figure 2. Effect of L. sativum on OVX-induced bone matrix and histological alterations using hematoxylin and eosin (H\&E), Masson trichrome, and alizarin red stains. (A) Control group showing average periosteum (black arrow), average cortex with regular dense lamellae (blue arrows), small osteocytes (yellow arrow) (H\&E), cortex with parallel regular collagen fibers (black arrow) (Masson trichrome), cortex reactive for alizarin red with regular lamellae with parallel small osteocytes (black arrow) (alizarin red). (B) Ovariectomized untreated animals showing thin eroded bony trabeculae (black arrow) with large osteocytes (blue arrow) and osteoblastic rimming (red arrow) (H\&E), irregular arrangement of collagen fibers in cortex (black arrow) (Masson trichrome), non-reactive cortex for alizarin red showing irregular lamellae (black arrow) (alizarin red). (C) Ovariectomized rats treated with $50 \mathrm{mg} / \mathrm{kg}$ L. sativum extract demonstrating bony trabeculae with irregular dense lamellae (black arrow), large osteocytes in large lacunae (blue arrow), and osteoblastic rimming (red arrow) (H\&E), regular arrangement of collagen fibers in trabeculae (yellow arrow) (Masson trichrome) and cortex less-reactive for stain (black arrow) (alizarin red). (D) Ovariectomized rats treated with $100 \mathrm{mg} / \mathrm{kg}$ L. sativum extract illustrating bony trabeculae (black arrow), large osteocytes in large lacunae (blue arrow) (H\&E), irregular arrangement of dense collagen fibers (yellow arrow) (Masson trichrome), and some reactivity for alizarin (black arrow) (alizarin red). (E) Estradiol-treated group displaying average trabeculae with dense lamella (black arrow) small osteocytes in small lacuna (blue arrow) (H\&E), irregular arrangement of collagen fibers in cortex (yellow arrow) (Masson trichrome), and frequent parallel small osteocytes reactive to alizarin red (black arrow) (alizarin red). (F) Table displaying the lesion scores for the different treatment groups. Nil, -; Mild, + ; Moderate, ++ ; Severe +++ .

Histopathological observations reported in this study are concurrent with a recent histological study highlighting the ability of L. sativum to protect against glucocorticoid-induced bone histological and morphometric pathological changes [29].

\subsubsection{Effect of L. sativum on Serum Biomarkers of Bone Formation and Resorption}

Serum markers of bone formation ALP activity and osteocalcin level were significantly decreased by ovariectomy by $36 \%$ and $25 \%$, respectively as compared to control values (Table 1 ). Treatment of ovariectomized rats with $L$. sativum ameliorated such pathological alterations. The high dose $(100 \mathrm{mg} / \mathrm{kg}$ ) prevented the decrease of both ALP and osteocalcin by $36 \%$ and $29 \%$ respectively, as compared to OVX animals. TRAP and CTXI are critical effectors mainly expressed by osteoclasts and play key roles in bone resorption. Therefore, they are excellent indicators of osteoclast activity [30] and their high levels have been linked to bone disorders including osteoporosis. The observed inhibition of their levels suggests a decrease in the intensity of osteoclastogenesis and osteoclast activity. The serum markers of bone resorption TRAP level and CTXI levels were elevated by ovariectomy. L. sativum in both doses (50 and $100 \mathrm{mg} / \mathrm{kg}$ ), as well as estradiol, significantly inhibited rising bone resorption markers TRAP and CTXI. The high dose of L. sativum (100 mg/kg) improved ALP and CTXI levels by $28 \%$ and $30 \%$, respectively, when compared to animals in the OVX group (Table 1 ). Thus, the anti-osteoporotic activity of the plant was confirmed by its ability to ameliorate reduced bone formation markers, serum ALP activity, as well as osteocalcin.

Table 1. Effect of L. sativum on serum markers of bone formation and resorption.

\begin{tabular}{|c|c|c|c|c|}
\hline & $\begin{array}{c}\text { ALP } \\
\text { (U/dL) }\end{array}$ & $\begin{array}{l}\text { Osteocalcin } \\
(\mathrm{pg} / \mathrm{mL})\end{array}$ & $\begin{array}{l}\text { TRAP } \\
\text { (U/dL) }\end{array}$ & $\begin{array}{c}\text { CTXI } \\
(\mathrm{ng} / \mathrm{mL})\end{array}$ \\
\hline Control & $28.65 \pm 2.71$ & $4.25 \pm 0.45$ & $2.25 \pm 0.32$ & $3.25 \pm 0.47$ \\
\hline OVX & $21.33 \pm 2.83^{a}$ & $2.68 \pm 0.28^{a}$ & $4.10 \pm 0.45^{a}$ & $5.47 \pm 0.58^{a}$ \\
\hline LS $50 \mathrm{mg} / \mathrm{kg}$ & $25.74 \pm 2.88$ & $3.15 \pm 0.32^{a}$ & $3.27 \pm 0.34^{\mathrm{a}}$ & $4.10 \pm 0.47^{\mathrm{a}, \mathrm{b}}$ \\
\hline LS $100 \mathrm{mg} / \mathrm{kg}$ & $27.61 \pm 2.80^{b}$ & $3.66 \pm 0.38^{b}$ & $2.94 \pm 0.25^{\mathrm{a}, \mathrm{b}}$ & $3.85 \pm 0.40^{b}$ \\
\hline E2 $25 \mathrm{mcg} / \mathrm{kg}$ & $28.47 \pm 2.90^{b}$ & $4.10 \pm 0.43^{b, c}$ & $2.44 \pm 0.32^{b, c}$ & $3.55 \pm 0.42^{b}$ \\
\hline
\end{tabular}

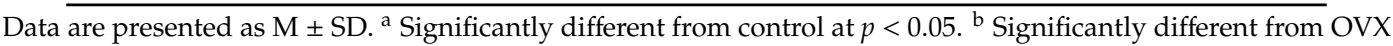
at $p<0.05$. ' Significantly different from LS $50 \mathrm{mg} / \mathrm{kg}$ at $p<0.05$. E2: estradiol, LS: L. sativum, ALP: alkaline phosphatase, TRAP: tartrate-resistant acid phosphatase, CTXI: carboxyterminal telopeptide, type I. 


\subsubsection{Effect of L. sativum on Ovariectomy-Induced Oxidative Stress in Bone Tissue}

Ovariectomized animals had reduced antioxidant defense in tissues of the femur with a depletion of SOD and GPx activities by $36 \%$ and 38\%, respectively, relative to control animals. However, treatment of ovariectomized rats with L. sativum significantly prevented the decreased enzymatic activities. In particular, the high dose $(100 \mathrm{mg} / \mathrm{kg})$ was able to normalize LDH and GPx values (Figure 3A,B). Assessment of lipid peroxide content in bone tissues, due to oxidative stress, showed high levels in femurs of ovariectomized rats by approximately, 70\% in comparison to controls. Treatment of L. sativum extract at 50 or $100 \mathrm{mg} / \mathrm{kg}$ significantly inhibited the rise in MDA values by 26 or 30, respectively, as compared to OVX values (Figure 3C). Estradiol, as a positive control, could normalize SOD, GPx, and MDA values (Figure 3A-C).

A

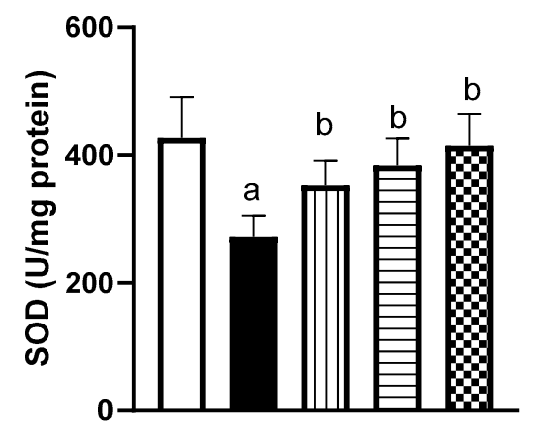

ש Control

- OVX

س LS $50 \mathrm{mg} / \mathrm{kg}$

ㄴ. $100 \mathrm{mg} / \mathrm{kg}$

E2 $25 \mathrm{mcg} / \mathrm{kg}$

B

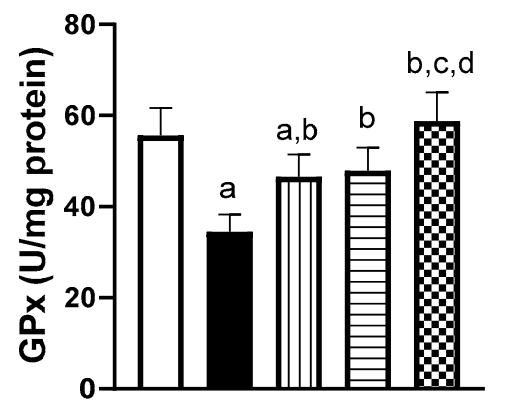

ש Control

- ovx

سS 50 mg/kg

D LS 100 mg/kg

E2 $25 \mathrm{mcg} / \mathrm{kg}$

C

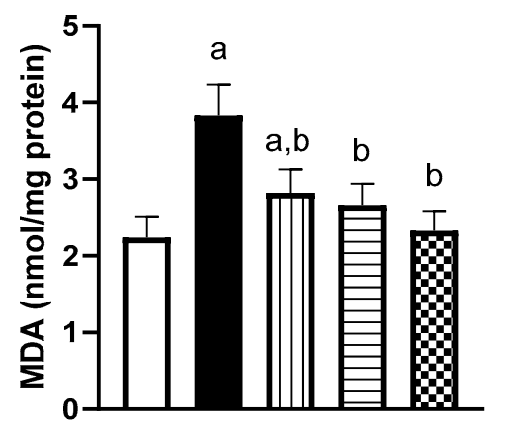

$\square$ Control
OVX
W LS $50 \mathrm{mg} / \mathrm{kg}$
$\square$ LS $100 \mathrm{mg} / \mathrm{kg}$
$\boldsymbol{\omega}$ E2 $25 \mathrm{mcg} / \mathrm{kg}$

Figure 3. Effect of L. sativum (LS) on superoxide dismutase (SOD) activity (A), glutathione peroxidase (GPx) activity (B) and malondialdehyde (MDA) content (C) in femur tissues of ovariectomized rats. Data are presented as $M \pm S D$. (a) Significantly different from control at $p<0.05$. (b) Significantly different from OVX at $p<0.05$. (c) Significantly different from LS $50 \mathrm{mg} / \mathrm{kg}$ at $p<0.05$. (d) Significantly different from LS $100 \mathrm{mg} / \mathrm{kg}$ at $p<0.05$. 
These data are in accordance with many previous studies that reported the anti-oxidant activity of L. sativum [19,31-33]. There is ample evidence linking oxidative stress to the development of post-menopausal osteoporosis [34,35]. Bone resorption has been shown to occur due to the disturbance in mineral tissue homeostasis resulting from increased reactive oxygen species (ROSs) [36]. ROSs have been recognized as signaling intermediates for osteoclasts, and their effects may be limited by antioxidants due to decreased in vivo resorption [37]. The role of antioxidants in preventing bone degeneration has been reviewed [38], to confirm that the observed antioxidant activities of L. sativum can be contributed to its anti-osteoporotic activities.

\subsubsection{Effect of L. sativum on RANKL and OPG mRNA Expression}

RANKL mRNA was significantly upregulated in the femur bones of ovariectomized rats by almost 9-fold relative to controls. This was accompanied by a $29 \%$ reduction in OPG expression in comparison to controls. The RANKL/OPG ratio rose significantly by approximately 1.6-fold. Nevertheless, treatment of rats with L. sativum (50 or $100 \mathrm{mg} / \mathrm{kg}$ ) significantly reduced ovariectomy-induced RANKL expression by $38 \%$ and $45 \%$ respectively, as compared to ovariectomized animals. In addition, L. sativum (50 or $100 \mathrm{mg} / \mathrm{kg}$ ) significantly enhanced mRNA expression of OPG by $47 \%$ or $80 \%$, respectively, as compared to ovariectomized rats. Estradiol normalized RANKL expression, enhanced OPG expression and significantly decreased the RANKL/OPG ratio as compared to control animals (Figure $4 \mathrm{~A}-\mathrm{C}$ ).

The detected RANKL upregulation, a marker of osteoclastic activity, in ovariectomized rats may have occurred as a result of oxidative stress. Oxidative stress and ROS have been previously associated with $R A N K L$ upregulation [39]. Conversely, antioxidants protected against $\mathrm{H}_{2} \mathrm{O}_{2}$-mediated upregulation of RANKL [40]. This observation is consistent with the enhancement of the mRNA expression in the bone formation marker OPG. Fundamentally, $O P G$, also known as osteoclastogenesis inhibitory factor (OCIF), is essential for bone remodeling, a normal process in which old bone is broken down and new bone is created to replace it. Further, L. sativum prevented the rise of RANKL/OPG ratio, which is an essential component in the regulation of bone metabolism [41]. Menopause has been reported to disrupt the RANKL/OPG system and enhance risk for osteoporosis [42]. In addition, the potential estrogenic activity of L. sativum cannot be excluded. Supplementation of L. sativum seed was reported to stimulate gonadotropin secretion in rabbits. This was attributed to its rich phytosterol content that activates estrogen receptors producing agonistic effects [43]. Furthermore, the volatile oil obtained by steam distillation of $L$. sativum was shown to exhibit an estrogenic effect accompanied by an increase in the weight of ovariectomized rats [44]. Thus, the estrogenic activity of the extract could have an important role in modulating RANKL/OPG mRNA expression and mediate the anti-osteoporotic activities of L. sativum. Determination of the estrogenic effect of $L$. sativum extract in ovariectomized rats should help prove such hypothesis which is yet to be determined. 
A

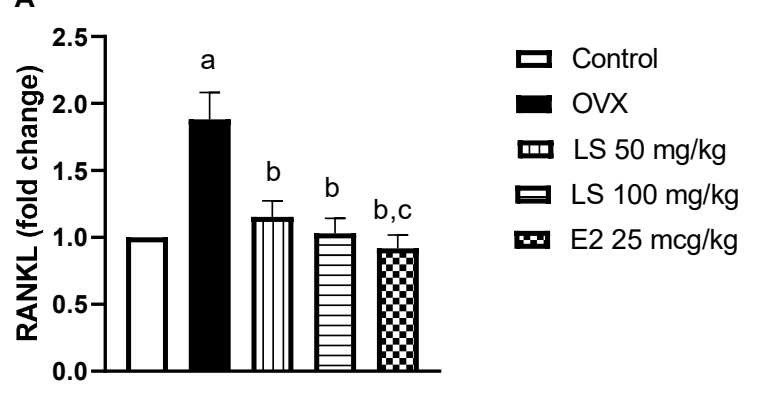

B
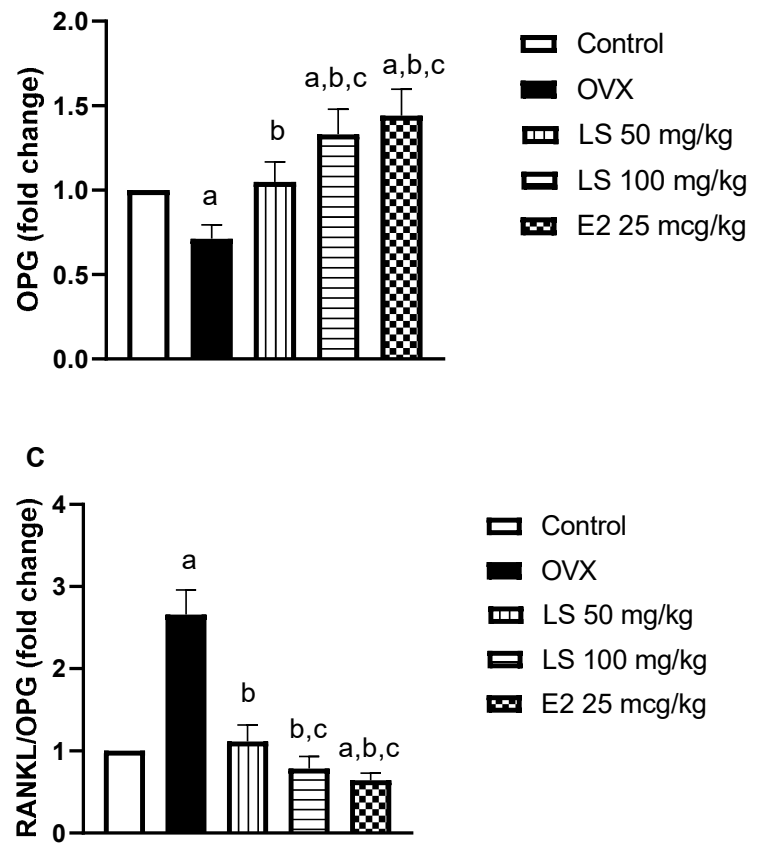

Figure 4. Effect of L. sativum (LS) on mRNA expression of receptor activator of nuclear factor kappa-B ligand (RANKL) and osteoprotegerin (OPG) and RANKL/OPG ratio in femur bones of ovariectomized rats. (A) The levels of RANKL mRNA transcripts; (B) the levels of OPG mRNA transcripts; (C) $R A N K L / O P G$ ratio. Data are expressed as means \pm SD. (a) Significantly different from control at $p<0.05$. (b) Significantly different from OVX at $p<0.05$. (c) Significantly different from LS $50 \mathrm{mg} / \mathrm{kg}$ at $p<0.05$.

\subsection{Metabolites Characterization of L. sativum Seed Extract via UPLC and GC/MS Analyses}

High-resolution UHPLC-PDA-ESI-MS was used for analysis of L. sativum seed methanolic extract using positive and negative ionization (Figure 5). Gradient elution of seed metabolites resulted in complete elution in $21 \mathrm{~min}$ and gave a complete profile of this genus's seed metabolome from Saudi Arabia. UPLC-MS has been employed for profiling of L. sativum sprouts leading to the identification of sinapine and acylated flavonoids as major constituents [45]. Representative UHPLC-MS traces of seed 100\% methanolic extract in (+/-) ESI modes are given (Figure 5). The two ionization modes have similar peak responses, except for glucosinolate peak 10, which showed preferential ionization in negative mode versus abundance of alkaloid i.e., peaks 3 and 16 in the early elution portion of the chromatogram ( $0-4 \mathrm{~min}$ ) as detected in positive ionization mode. A stronger response was observed in negative modes for fatty acids showing late elution, and as expectedly detected between $\mathrm{rt}$ (retention times)16 and $18 \mathrm{~min}$. MS data (accurate molecular ion mass and fragmentation pattern), UV spectra, and elution times were factors in determining metabolite assignment relative to reports on Lepidium metabolites as shown in (Table 2). Classes of metabolites that were identified include flavonoids, 
alkaloids, glycoalkaloids, glucosinolates, phenolic/fatty acids, and coumarins with alkaloids and glucosinolates as the most abundant classes.

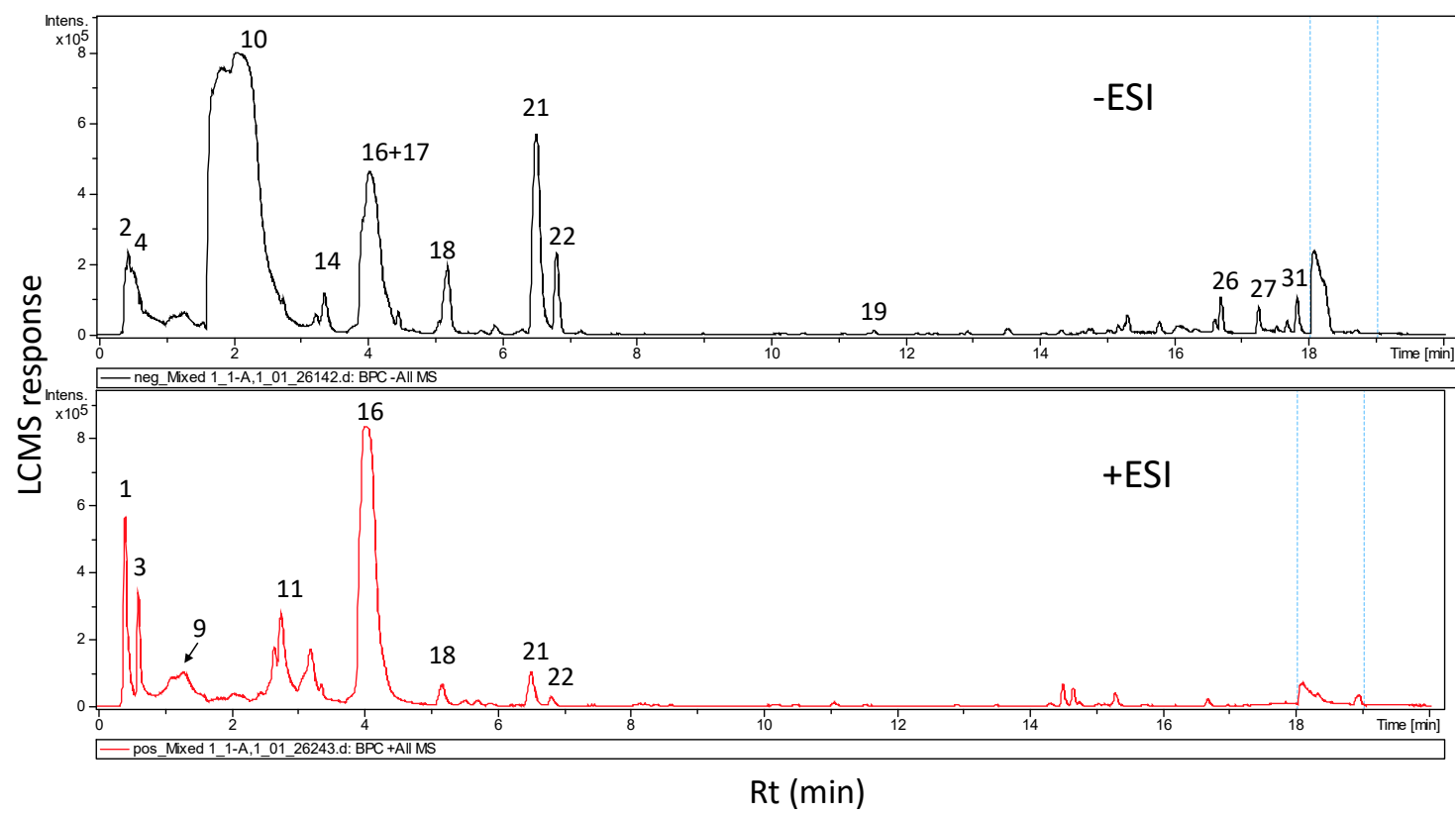

Figure 5. Representative UHPLC-MS base peak chromatogram of L. sativum $100 \%$ methanol seed extract in negative mode (black color) and positive (red color) ionization mode. Peak numbers follow those listed in Table 2. (Rt.: retention time).

\subsubsection{Alkaloids}

Alkaloids eluting in the earlier elution region of the chromatogram were detected almost exclusively in the positive ionization mode due to presence of nitrogen atoms. The identified alkaloids included a glycoalkaloid peak $3 \mathrm{rt} 0.5 \mathrm{~min}\left([\mathrm{M}+\mathrm{H}]^{+} 337.1384, \mathrm{C}_{16} \mathrm{H}_{21} \mathrm{~N}_{2} \mathrm{O}_{6}\right)$ and aglycone in peaks rt $2.9 \mathrm{~min}$ $\left([\mathrm{M}+\mathrm{H}]^{+} 347.1204, \mathrm{C}_{20} \mathrm{H}_{19} \mathrm{~N}_{4} \mathrm{O}_{2}\right)$ and $\mathrm{rt} 3.7 \mathrm{~min}\left([\mathrm{M}+\mathrm{H}]^{+} 361.167, \mathrm{C}_{21} \mathrm{H}_{21} \mathrm{~N}_{4} \mathrm{O}_{2}\right)$. Peak 3 showed a loss of $30 \mathrm{amu}$ and $162 \mathrm{amu}$ in respective fragment ions at $\mathrm{m} / \mathrm{z} 347$ and $\mathrm{m} / \mathrm{z} 174$, indicative of methoxy and hexosyl moieties and confirming its annotation as semilepidinoside A. Aglycone peaks 13 and 14 showing later elution were annotated as lepdine $\mathrm{B} / \mathrm{D} / \mathrm{E} / \mathrm{F}$ and lepidine $\mathrm{C}$, respectively, all belong to the imidazole alkaloid class type typical of L. sativum [12]. A fragment ion appearing at $m / z 174$ was detected in MS fragmentation of imidazole alkaloids and its glycoside and served in its identification. Sinapine was present as the major alkaloid detected in peak $16[\mathrm{M}+\mathrm{H}]^{+}$at $\mathrm{m} / \mathrm{z} 310.1657$ and displaying characteristic fragment ions at $m / z 251$ and 207 [45], and previously reported in L. sativum sprouts.

\subsubsection{Glucosinolates}

Benzyl glucosinolate (glucotropaeolin) was identified as major glucosinolate in L. sativum (peak $10, \mathrm{~m} / z$ 408.0463, $\mathrm{C}_{14} \mathrm{H}_{19} \mathrm{NO}_{9} \mathrm{~S}_{2}{ }^{-}$) and showing loss of $162 \mathrm{amu}$, previously reported in in LC/MS analysis of Lepidium meyenii $[46,47]$. The cytotoxic and antimicrobial properties of Lepidium latifolium hydrodistillate are mainly due to the presence of glucosinolates [47]. In particular, isothiocyanate, which is a main degradation sulfur volatile allyl is thought to be involved in these activities. Whether allyl isothiocyanate is also present in L. sativum has yet to be reported. Analysis of sulfur aroma compounds via GC/MS analysis can provide a complete profile of glucosinolate hydrolysis products [48]. 
Table 2. Metabolites identified in $100 \%$ methanol extracts of $L$. sativum seeds via UHPLC-PDA-ESI-MS in both negative and positive ionization modes. Nd = not detected, + or - denotes molecular ion charge in molecular formula.

\begin{tabular}{|c|c|c|c|c|c|c|c|c|}
\hline $\begin{array}{l}\text { Peak } \\
\text { No }\end{array}$ & $\begin{array}{c}\text { RT } \\
(\min )\end{array}$ & $\begin{array}{c}\text { UV } \\
(\mathrm{nm})\end{array}$ & Mol. Ion & Mol. Formula & Name & Class & $\begin{array}{l}\text { Error } \\
(\mathrm{ppm})\end{array}$ & $\begin{array}{c}\text { MSMS } \\
\text { Fragments }\end{array}$ \\
\hline 1 & 0.3 & $\mathrm{Nd}$ & 705.1815 & $\mathrm{C}_{36} \mathrm{H}_{35} \mathrm{O}_{15}^{+}$ & Hexahydroxy-biflavanone-O-hexoside & Flavonoid & -0.1 & 543 \\
\hline 2 & 0.35 & $\mathrm{Nd}$ & 325.1135 & $\mathrm{C}_{12} \mathrm{H}_{21} \mathrm{O}_{10}{ }^{+}$ & Unknown disaccharide & Sugar & 2.3 & 223,127 \\
\hline 3 & 0.5 & 280 & 337.1384 & $\mathrm{C}_{16} \mathrm{H}_{2} 1 \mathrm{~N}_{2} \mathrm{O}_{6}^{+}$ & Semilepidinoside A & Glycoalkaloid & 0.9 & 347,174 \\
\hline 4 & 0.52 & $\mathrm{Nd}$ & 719.2016 & $\mathrm{C}_{37} \mathrm{H}_{37} \mathrm{O}_{15}^{+}$ & Dimethoxycinnamoyl-O-feruloyl-O-caffeoylquinic acid & Phenolic acid & -5.4 & $539,377,341$ \\
\hline 5 & 0.5 & $\mathrm{Nd}$ & 723.1882 & $\mathrm{C}_{36} \mathrm{H}_{37} \mathrm{O}_{16}{ }^{+}$ & Tetrahydroxyflavan-tetrahydroxyflavanone hexoside & Flavonoid & 4.9 & \\
\hline 6 & 0.57 & $\mathrm{Nd}$ & 539. 1378 & $\mathrm{C}_{24} \mathrm{H}_{27} \mathrm{O}_{14}{ }^{-}$ & Unknown & Sugar & 1.4 & 377 \\
\hline 7 & 0.6 & 280 & 337.1384 & $\mathrm{C}_{16} \mathrm{H}_{21} \mathrm{~N}_{2} \mathrm{O}_{6}^{+}$ & Semilepidinoside A (isomer) & Glycoalkaloid & 2.9 & 174 \\
\hline 8 & 0.7 & $\mathrm{Nd}$ & 337.1409 & $\mathrm{C}_{12} \mathrm{H}_{17} \mathrm{O}_{8}^{+}$ & Aconitic acid-O-hexoside & Organic acid & 7.7 & 175 \\
\hline 9 & 1.1 & 280 & 347.1476 & $\mathrm{C}_{20} \mathrm{H}_{19} \mathrm{~N}_{4} \mathrm{O}_{2}^{+}$ & Lepidine (B/D/E/F) & Alkaloid & 7.4 & 174 \\
\hline 10 & 1.9 & 280 & 408.0463 & $\mathrm{C}_{14} \mathrm{H}_{19} \mathrm{NO}_{9} \mathrm{~S}_{2}^{-}$ & Benzyl-glucosinolate (Glucotropaeolin) & Glucosinolate & - & $246,212,96$ \\
\hline 11 & 2.3 & 280 & 359.1525 & $\mathrm{C}_{20} \mathrm{H}_{23} \mathrm{O}_{6}^{-}$ & Lariciresinol & Lignan & 3.1 & 345,298 \\
\hline 12 & 2.6 & 280 & 361.1648 & $\mathrm{C}_{21} \mathrm{H}_{21} \mathrm{~N}_{4} \mathrm{O}_{2}^{+}$ & Lepidine C & Alkaloid & 3 & 174 \\
\hline 13 & 2.9 & $\mathrm{Nd}$ & 347.167 & $\mathrm{C}_{20} \mathrm{H}_{19} \mathrm{~N}_{4} \mathrm{O}_{2}^{+}$ & Lepidine (B/D/E/F) & Alkaloid & & \\
\hline 14 & 3.2 & 280 & 361.167 & $\mathrm{C}_{21} \mathrm{H}_{21} \mathrm{~N}_{4} \mathrm{O}_{2}^{+}$ & Lepidine $\mathrm{C}$ & Alkaloid & 3.0 & 214 \\
\hline 15 & 3.4 & 280.5 & 425.0897 & $\mathrm{C}_{22} \mathrm{H}_{17} \mathrm{O}_{9}^{-}$ & Unknown & Flavonoid & -4.5 & 359 \\
\hline 16 & 3.9 & 328 & 310.1657 & $\mathrm{C}_{16} \mathrm{H}_{25} \mathrm{NO}_{5}^{+}$ & Sinapine & Alkaloid & 0.6 & 251,207 \\
\hline 17 & 4.1 & 328 & 294.1348 & - & Unknown & Glucosinolate & & 96 \\
\hline 18 & 5.0 & $\mathrm{Nd}$ & 369.1191 & $\mathrm{C}_{17} \mathrm{H}_{21} \mathrm{O}_{9}^{+}$ & O-Caffeoylquinic acid methyl ester & Phenolic acid & -2.5 & \\
\hline 19 & 5.8 & $\mathrm{Nd}$ & 225.0745 & $\mathrm{C}_{11} \mathrm{H}_{13} \mathrm{O}_{5}^{+}$ & Trihydroxycinnamic acid-O-di-methyl ester & Phenolic acid & 5.3 & 175 \\
\hline 20 & 6.1 & 328 & 207.0642 & $\mathrm{C}_{11} \mathrm{H}_{9} \mathrm{O}_{4}^{-}$ & Dimethylesculetin & Coumarin & 0.4 & 175 \\
\hline 21 & 6.5 & 329 & 339.0722 & $\mathrm{C}_{15} \mathrm{H}_{15} \mathrm{O}_{9}$ & Esculin & Coumarin & -4.6 & 223,179 \\
\hline 22 & 6.9 & 327 & 613.1870 & $\mathrm{C}_{26} \mathrm{H}_{33} \mathrm{~N}_{2} \mathrm{O}_{15}{ }^{+}$ & Unknown & & & \\
\hline 23 & 11.6 & 326 & 591.1684 & $\mathrm{C}_{28} \mathrm{H}_{31} \mathrm{O}_{14}^{-}$ & Acacetin-O-rutinoside & Flavonoid & 5.9 & 283 \\
\hline 24 & 12.2 & $\mathrm{Nd}$ & 329.2319 & $\mathrm{C}_{18} \mathrm{H}_{33} \mathrm{O}_{5}^{-}$ & Trihydroxy octadecenoic acid & Hydroxy fatty acid & 4.4 & 283 \\
\hline 25 & 16.5 & $\mathrm{Nd}$ & 271.2299 & $\mathrm{C}_{16} \mathrm{H}_{31} \mathrm{O}_{3}^{-}$ & Hydroxy hexadecanoic acid & Hydroxy fatty acid & 3.5 & 225,116 \\
\hline 26 & 16.6 & $\mathrm{Nd}$ & 277.2173 & $\mathrm{C}_{18} \mathrm{H}_{29} \mathrm{O}_{2}^{-}$ & Linolenic acid & Unsaturated fatty acid & 4.5 & 251,211 \\
\hline 27 & 17.2 & $\mathrm{Nd}$ & 279.2330 & $\mathrm{C}_{18} \mathrm{H}_{31} \mathrm{O}_{2-}$ & Linoleic acid & Unsaturated fatty acid & 4 & 211 \\
\hline 28 & 17.3 & $\mathrm{Nd}$ & $425.287+$ & $\mathrm{C}_{24} \mathrm{H}_{41} \mathrm{O}_{6}{ }^{+}$ & Unknown steroid & Steroid & 3.3 & \\
\hline 29 & 17.5 & $\mathrm{Nd}$ & 327.2888 & $\mathrm{C}_{20} \mathrm{H}_{39} \mathrm{O}_{3}^{-}$ & Hydroxy eicosanoic acid & Hydroxy fatty acid & 5.1 & - \\
\hline 30 & 17.7 & $\mathrm{Nd}$ & 353.3044 & $\mathrm{C}_{22} \mathrm{H}_{41} \mathrm{O}_{3}^{-}$ & Oxo docosanoic acid & Oxygenated fatty acid & 4.9 & - \\
\hline 31 & 17.8 & $\mathrm{Nd}$ & 281.2488 & $\mathrm{C}_{18} \mathrm{H}_{33} \mathrm{O}_{2}^{-}$ & Oleic acid & Unsaturated fatty acid & -0.7 & \\
\hline 32 & 18.8 & $\mathrm{Nd}$ & 311.2941 & $\mathrm{C}_{20} \mathrm{H}_{39} \mathrm{O}_{2}^{+}$ & Eicosenoic acid & Unsaturated fatty acid & 1.2 & \\
\hline
\end{tabular}




\subsubsection{Phenolic Acids \& Flavonoids/Lignans}

Major contributions to the antioxidant effects of food materials are due to the presence of phenolic acids. They are present in free or conjugated forms, such as flavonoids, and are a common class of secondary metabolites [25]. In this study, three phenolic acid conjugates were detected exclusively in negative ion mode (Table 1 ) in peaks $(4,18$, and 19) as monomer or dimer of methylated caffeic, ferulic, and dimethoxy cinnamic acids.

Few flavonoids of the flavanone subclass and one lignan peak were identified in peaks 1, 5, 11, 15, and 23. Lariciresinol (peak 11) was identified from its characteristic UV absorption at $280 \mathrm{~nm}$ and molecular ion $\left[\mathrm{M} \mathrm{-} \mathrm{H}^{-}\right]$at $m / z 359.1525$ and displaying fragment ions at $m / z 345$ and 298. Lariciresinol $4^{\prime}$-O- $\beta$-d-glucopyranoside was previously obtained from L. apetalum seeds [49].

\subsubsection{Coumarins}

Two coumarins of esculin aglycone (hydroxycoumarin) were annotated in L. sativum as esculin-O-hexoside (peak $21\left[\mathrm{M} \mathrm{-} \mathrm{H}^{-}\right]$at $\mathrm{m} / \mathrm{z} 339.0722$ ) and showing loss of $162 \mathrm{amu}$ and dimethylesculin (peak $20\left[\mathrm{M} \mathrm{-} \mathrm{H}^{-}\right]$at $\mathrm{m} / \mathrm{z} 207.0642$ ), and both displaying UV max at $330 \mathrm{~nm}$ typical of coumarin. Esculin was previously reported in Lepidium in a response to umbelliferone uptake by roots [50].

\subsubsection{Fatty Acids}

Several unsaturated fatty acids were identified after negative ionization MS, during the final part of the chromatographic run (16-18 min). Negative ion MS spectra of the unsaturated fatty acids: (linolenic acid, peak 26), (linoleic acid, peak 27), (oleic acid, peak 31), (eicosenoic acid, peak 32) were interpreted using exact masses of $277.2173,279.233,281.2488$, and 311.2941 and an expected molecular formula of $\mathrm{C}_{18} \mathrm{H}_{29} \mathrm{O}_{2}{ }^{-}, \mathrm{C}_{18} \mathrm{H}_{31} \mathrm{O}_{2}{ }^{-}, \mathrm{C}_{18} \mathrm{H}_{33} \mathrm{O}_{2}{ }^{-}$, and $\mathrm{C}_{20} \mathrm{H}_{39} \mathrm{O}_{2}{ }^{-}$, respectively. L. sativum seed oil showed anti-inflammatory, anti-oxidant, and antimicrobial activities [51], attributed to the presence of unsaturated fatty acids in L. sativum seed, which potentially can serve as functional food for hyperlipidemia. Negative ionization MS also revealed the presence of a few hydroxy fatty acids that eluted in peaks 24,25 , and 29. Peak number 25 was identified as hydroxy hexadecanoic acid $[\mathrm{M}-\mathrm{H}]^{-}$ $m / z$ 271.2299, showing fragment ions at $m / z 225$ suggestive for the respective loss of $\mathrm{CH}_{2} \mathrm{O}_{2}$ [52]. This is an unprecedented report for hydroxyl fatty acids in L. sativum and is of increasing interest owing to its reported antimicrobial, cytotoxic, and anti-inflammatory actions [53]. Whether these oxylipids contribute to Lepidium seed's reported anti-inflammatory and anti-microbial properties [51] has yet to be confirmed.

\subsubsection{Volatile Compounds}

Volatile constituents of the plant were assessed utilizing headspace solid-phase microextraction (SPME) and GC/MS (Figure 6). The results (Table 3) showed enrichment of sesquiterpene hydrocarbons $(35.9 \%)$, followed by aromatic volatile constituents $(20.7 \%)$, volatile alcohols $(20.6 \%)$, volatile acids $(7.06 \%)$, and aliphatic hydrocarbons $(4.82 \%)$ in L. sativum aroma blend. $\alpha$-Copaene represented the major sesquiterpene hydrocarbons (22.7\%), whereas 1-hexanol was the major alcohol (12.2\%).

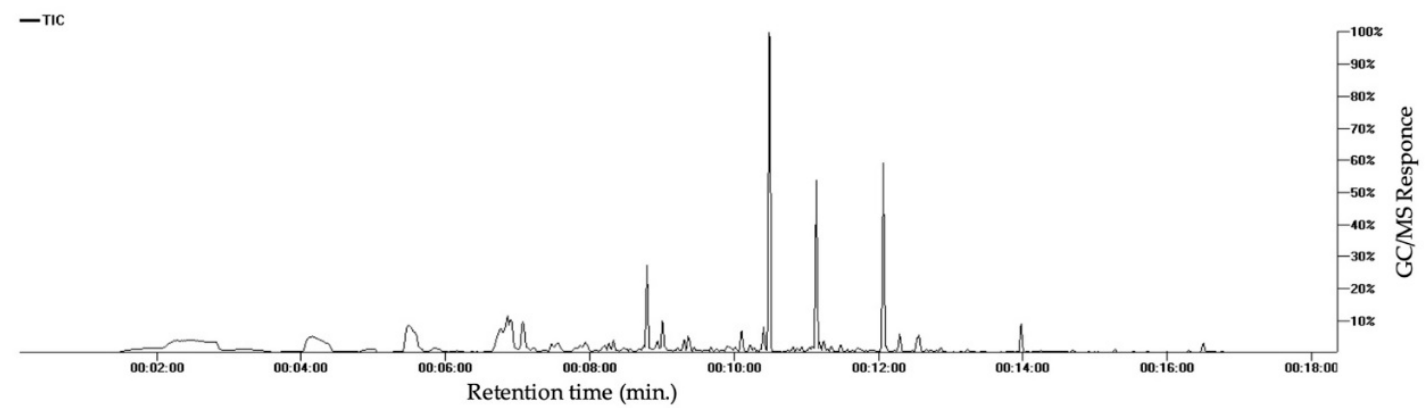

Figure 6. Representative SPME-GC-MS chromatogram of L. sativum. 
Table 3. Relative percentage of components in L. sativum seed analyzed using solid-phase microextraction (SPME)-GC-MS, $n=3$.

\begin{tabular}{|c|c|c|c|c|c|c|c|}
\hline No. & CAS no. & Name & Class & RT & KI & Expected KI & $\%$ \\
\hline 1 & $64-19-7$ & Acetic acid & Acid & 2.811 & 591 & 610 & 1.95 \\
\hline 2 & $111-27-3$ & 1-Hexanol & Alcohol & 5.473 & 843 & 868 & 12.21 \\
\hline 3 & $142-62-1$ & Caproic acid & Acid & 6.8486 & 973 & 990 & 1.70 \\
\hline 4 & $72237-36-6$ & 4-Hexenyl acetate & Ester & 7.2139 & 1008 & 1020 & 0.69 \\
\hline 5 & $535-77-3$ & $m$-Cymene & Monoterpene hydrocarbon & 7.4558 & 1030 & 1023 & 1.29 \\
\hline 6 & $100-51-6$ & Benzyl alcohol & Aromatic & 7.5425 & 1038 & 1036 & 1.21 \\
\hline 7 & $111-87-5$ & 1-Óctanol & Alcohol & 7.9197 & 1073 & 1071 & 1.41 \\
\hline 8 & $30086-02-3$ & 3,5-Octadien-2-one & Ketone & 7.9493 & 1076 & 1073 & 0.84 \\
\hline 9 & $99-86-5$ & $\alpha$-Terpinene & Monoterpene hydrocarbon & 8.1916 & 1099 & 1017 & 0.59 \\
\hline 10 & $1120-21-4$ & Undecane & Aliphatic hydrocarbon & 8.2512 & 1104 & 1100 & 0.99 \\
\hline 11 & $124-19-6$ & Nonanal & Aldehyde & 8.3168 & 1110 & 1104 & 1.21 \\
\hline 14 & $140-29-4$ & Benzyl cyanide & Nitrogenous & 8.7354 & 1150 & 1144 & 0.97 \\
\hline 16 & $124-07-2$ & Caprylic acid & Acid & 8.924 & 1167 & 1180 & 0.91 \\
\hline 17 & $143-08-8$ & 1-Nonanol & Alcohol & 8.9942 & 1174 & 1173 & 3.78 \\
\hline 19 & $91-20-3$ & Naphthalene & Aromatic & 9.2767 & 1200 & 1182 & 0.21 \\
\hline 20 & $112-40-3$ & Dodecane & Aliphatic hydrocarbon & 9.2915 & 1202 & 1200 & 1.21 \\
\hline 21 & $140-67-0$ & Estragole & Ether & 9.3507 & 1208 & 1196 & 1.92 \\
\hline 22 & $112-31-2$ & Decanal & Aldehyde & 9.3689 & 1210 & 1206 & 0.85 \\
\hline 23 & $17301-23-4$ & 2,6-Dimethylundecane & Aliphatic hydrocarbon & 9.4331 & 1217 & 1210 & 0.41 \\
\hline 28 & $112-05-0$ & Nonanoic acid & Acid & 9.8915 & 1265 & 1273 & 0.59 \\
\hline 30 & $14371-10-9$ & Cinnamaldehyde & Aldehyde & 10.0882 & 1286 & 1270 & 2.65 \\
\hline 31 & $1197-15-5$ & Alpha-Terpinen-7-al & Aldehyde & 10.2019 & 1298 & 1283 & 0.45 \\
\hline 32 & $629-50-5$ & Tridecane & Aliphatic hydrocarbon & 10.2611 & 1304 & 1300 & 0.29 \\
\hline 33 & $104-54-1$ & Cinnamyl alcohol & Alcohol & 10.3897 & 1318 & 1312 & 3.23 \\
\hline 36 & $80-26-2$ & $\alpha$-Terpinyl acetate & Ester & 10.8007 & 1361 & 1350 & 0.49 \\
\hline 37 & $104-61-0$ & $\gamma$-Nonalactone & Lactone & 10.9187 & 1373 & 1363 & 0.42 \\
\hline 38 & $622-78-6$ & Benzyl Isothiocyanate & Nitrogenous & 10.9927 & 1381 & 1364 & 0.15 \\
\hline 39 & $77-68-9$ & 1,3-Pentanediol, 2, 2,4-trimethyl-, 1-isobutyrate & Ester & 11.0303 & 1385 & 1380 & 0.48 \\
\hline 40 & $22469-52-9$ & Cyclosativene & Sesquiterpene hydrocarbon & 11.065 & 1389 & 1368 & 0.46 \\
\hline 41 & $3856-25-5$ & Alpha-Copaene & Sesquiterpene hydrocarbon & 11.1217 & 1395 & 1376 & 22.70 \\
\hline 42 & $629-59-4$ & Tetradecane & Aliphatic hydrocarbon & 11.1699 & 1400 & 1400 & 1.00 \\
\hline 43 & $3650-28-0$ & Sativene & Sesquiterpene hydrocarbon & 11.3348 & 1416 & 1396 & 0.53 \\
\hline 44 & $475-20-7$ & Longifolene & Sesquiterpene hydrocarbon & 11.4616 & 1428 & 1405 & 0.85 \\
\hline
\end{tabular}


Table 3. Cont.

\begin{tabular}{|c|c|c|c|c|c|c|c|}
\hline No. & CAS no. & Name & Class & RT & KI & Expected KI & $\%$ \\
\hline 45 & $87-44-5$ & Caryophyllene & Sesquiterpene hydrocarbon & 11.5517 & 1437 & 1419 & 0.13 \\
\hline 46 & $91-64-5$ & Coumarin & Lactone & 11.6997 & 1451 & 1441 & 0.41 \\
\hline 47 & - & Unknown 6 & Aromatic & 12.0477 & 1485 & - & 16.60 \\
\hline 48 & $629-62-9$ & Pentadecane & Aliphatic hydrocarbon & 12.0883 & 1489 & 1500 & 0.56 \\
\hline 49 & $10208-80-7$ & $\alpha$-Muurolene & Sesquiterpene hydrocarbon & 12.2757 & 1507 & 1440 & 2.82 \\
\hline 50 & $39029-41-9$ & g-Cadinene & Sesquiterpene hydrocarbon & 12.4499 & 1524 & 1513 & 0.08 \\
\hline 51 & 483-76-1 & $\delta$-Cadinene & Sesquiterpene hydrocarbon & 12.518 & 1531 & 1524 & 2.12 \\
\hline 52 & $483-77-2$ & Calamenene & Sesquiterpene hydrocarbon & 12.5412 & 1533 & 1523 & 2.23 \\
\hline 53 & $29837-12-5$ & Cubenene & Sesquiterpene hydrocarbon & 12.6469 & 1543 & 1532 & 0.25 \\
\hline 54 & 21391-99-1 & $\alpha$-Calacorene & Sesquiterpene hydrocarbon & 12.7865 & 1557 & 1542 & 0.18 \\
\hline 55 & $629-73-2$ & Cetene & Sesquiterpene hydrocarbon & 13.1248 & 1590 & 1592 & 0.09 \\
\hline 56 & $544-76-3$ & Hexadecane & Aliphatic hydrocarbon & 13.2144 & 1598 & 1600 & 0.35 \\
\hline 57 & $119-61-9$ & Benzophenone & Ketone & 13.7904 & 1662 & 1635 & 0.09 \\
\hline 59 & - & Unknown 8 & Unknown & 13.9587 & 1680 & - & 3.49 \\
\hline 60 & $544-63-8$ & Myristic acid & Acid & 14.6776 & 1759 & 1768 & 0.19 \\
\hline 61 & $120-51-4$ & Benzyl Benzoate & Ester & 14.8996 & 1784 & 1762 & 0.05 \\
\hline 63 & $1002-84-2$ & Pentadecanoic acid & Acid & 15.5098 & 1848 & 1867 & 0.10 \\
\hline 65 & $373-49-9$ & Palmitoleic acid & Acid & 16.2828 & 1929 & 1951 & 0.12 \\
\hline 66 & $57-10-3$ & Palmitic acid & Acid & 16.4798 & 1949 & 1968 & $\begin{array}{c}1.51 \\
100.00\end{array}$ \\
\hline
\end{tabular}


Based on the analysis performed in this study, it could be concluded that the osteoprotective effect of L. sativum is likely due to a synergistic effect of its various classes of metabolites i.e., alkaloids, lignans, phenolic acids, etc. For example, glucosinolates (peak 10) stimulated bone formation in young rats and in MG-63 cells [54]. Phenolic acids were also investigated for their osteoprotective effect in ovariectomized rats, with ferulic, caffeic, $p$-coumaric, and chlorogenic acids to counteract skeletal changes caused by estrogen deficiency in ovariectomized rats [55]. Plant lignans have been shown to provide estrogenic support and antioxidant and anti-inflammatory activity. Lariciresinol, a lignan precursor detected in peak 11, increases bone formation and significantly inhibits resorption.

Identified coumarin, esculin (peak 21) is reported for its osteoprotective effect mediated via modulation of bone metabolism by reducing osteoclastogenesis caused by receptor activator of NF- $\mathrm{KB}$ ligand (RANKL) and transduction signals in an osteoporosis model of ovariectomized rats [56]. Animal models have suggested that fatty acids as linolenic acid (omega-3), a major oxylipid in L. sativum (peak 26) could reduce postmenopausal bone loss. A significantly lower amount of bone was lost at the lumbar vertebrae and femurs of ovariectomized mice receiving a high-omega-3 diet [57]. In addition, it was observed in a clinical study that osteocalcin and procollagen were augmented in the linolenic acid supplemented groups [58]. Thus, L. sativum has been suggested for the management of postmenopausal osteoporosis and prevention of estrogen deficiency-induced fractures [59].

\section{Conclusions}

L. sativum ameliorates ovariectomy-induced bone injury in rats. This is evidenced by increasing bone weight, enhancing bone formation biomarkers (LDH and osteocalcin), as well as its free radicle scavenging activity of the extract. Moreover, it ameliorates the rise in the markers of bone resorption carboxyterminal telopeptide, type I (CTXI) and tartrate-resistant acid phosphatase (TRAP) and modulates $R A N K L / O P G$ expression. The synergy between the various constituents present in L. sativum most likely plays a contributing role in the osteoprotective effects of $L$. sativum. The current data not only support the folk use of L. sativum as a bone healer but also reveal the nature of bio-actives responsible for the observed activity and extraction action mechanism. In addition, our findings warrant further experimental and clinical studies. Whether the improvement in osteoporosis is mediated via an estrogenic effect for L. sativum extract has yet to be determined. These results are just a hint and need to be followed by testing isolated compounds using the same bioassay.

Author Contributions: H.M.A., M.M.A. and A.B.A.-N. conceptualization; H.M.A. funding acquisition; M.A.F., M.M.A., M.Z.N., B.G.E., A.E.K., and A.M.M. methodology, investigation and wrote the first draft of the manuscript. M.K.S. reviewed the manuscript. All authors have read and agreed to the published version of the manuscript.

Funding: This project was funded by the Deanship of Scientific Research (DSR) at King Abdulaziz University, Jeddah, under grant no. (RG-14-166-40). The authors, therefore, acknowledge with thanks DSR's technical and financial support.

Conflicts of Interest: The authors declare no conflict of interest.

\section{References}

1. Aghebati-Maleki, L.; Dolati, S.; Zandi, R.; Fotouhi, A.; Ahmadi, M.; Aghebati, A.; Nouri, M.; Kazem Shakouri, S.; Yousefi, M. Prospect of mesenchymal stem cells in therapy of osteoporosis: A review. J. Cell. Physiol. 2019, 234, 8570-8578. [CrossRef] [PubMed]

2. Elshal, M.F.; Almalki, A.L.; Hussein, H.K.; Khan, J.A. Synergistic antiosteoporotic effect of Lepidium sativum and alendronate in glucocorticoid-induced osteoporosis in Wistar rats. Afr. J. Tradit. Complement. Altern. Med. 2013, 10, 267-273. [CrossRef] [PubMed]

3. An, J.; Yang, H.; Zhang, Q.; Liu, C.; Zhao, J.; Zhang, L.; Chen, B. Natural products for treatment of osteoporosis: The effects and mechanisms on promoting osteoblast-mediated bone formation. Life Sci. 2016, 147, 46-58. [CrossRef] [PubMed]

4. Caracchini, G.; Cavalli, L. Severe osteoporosis: Diagnosis of femoral fractures. Clin. Cases Miner. Bone Metab. 2010, 7, 97. [PubMed] 
5. Wu, C.-H.; Kao, I.-J.; Hung, W.-C.; Lin, S.-C.; Liu, H.-C.; Hsieh, M.-H.; Bagga, S.; Achra, M.; Cheng, T.-T.; Yang, R.-S. Economic impact and cost-effectiveness of fracture liaison services: A systematic review of the literature. Osteoporos. Int. 2018, 29, 1227-1242. [CrossRef]

6. $\quad$ Peng, Y.-L.; Hu, H.-Y.; Luo, J.-C.; Hou, M.-C.; Lin, H.-C.; Lee, F.-Y. Alendronate, a bisphosphonate, increased upper and lower gastrointestinal bleeding: Risk factor analysis from a nationwide population-based study. Osteoporos. Int. 2014, 25, 1617-1623. [CrossRef] [PubMed]

7. Russo, J.; Russo, I.H. The role of estrogen in the initiation of breast cancer. J. Steroid Biochem. Mol. Biol. 2006, 102, 89-96. [CrossRef] [PubMed]

8. Horcajada, M.-N.; Offord, E. Naturally plant-derived compounds: Role in bone anabolism. Curr. Mol. Pharmacol. 2012, 5, 205-218. [CrossRef]

9. Abdel-Naim, A.B.; Alghamdi, A.A.; Algandaby, M.M.; Al-Abbasi, F.A.; Al-Abd, A.M.; Eid, B.G.; Abdallah, H.M.; El-Halawany, A.M. Rutin isolated from Chrozophora tinctoria enhances bone cell proliferation and ossification markers. Oxid. Med. Cell. Longev. 2018, 2018. [CrossRef] [PubMed]

10. Rahman, M.A.; Mossa, J.S.; Al-Said, M.S.; Al-Yahya, M.A. Medicinal plant diversity in the flora of Saudi Arabia 1: A report on seven plant families. Fitoterapia 2004, 75, 149-161. [CrossRef] [PubMed]

11. Vinti Dixit, J.R., III; Kumar, I.; Palandurkar, K.; Giri, R.; Giri, K. Lepidium sativum: Bone healer in traditional medicine, an experimental validation study in rats. J. Family Med. Prim. Care 2020, 9, 812.

12. Maier, U.H.; Gundlach, H.; Zenk, M.H. Seven imidazole alkaloids from Lepidium sativum. Phytochemistry 1998, 49, 1791-1795. [CrossRef]

13. Fan, Q.-L.; Zhu, Y.-D.; Huang, W.-H.; Qi, Y.; Guo, B.-L. Two new acylated flavonol glycosides from the seeds of Lepidium sativum. Molecules 2014, 19, 11341-11349. [CrossRef]

14. Al-Asmari, A.K.; Athar, M.T.; Al-Shahrani, H.M.; Al-Dakheel, S.I.; Al-Ghamdi, M.A. Efficacy of Lepidium sativum against carbon tetra chloride induced hepatotoxicity and determination of its bioactive compounds by GC/MS. Toxicol. Rep. 2015, 2, 1319-1326. [CrossRef] [PubMed]

15. El-Haroun, H.; Soliman, M.; El-Gawad, A. Comparative Study on the Possible Protective Effect of Lepidium Sativum versus Teriparatide in Induced Osteoporosis in Adult Male Guinea Pigs. Egypt. J. Histol. 2020. [CrossRef]

16. bin Abdullah Juma, A.b.H. The effects of Lepidium sativum seeds on fracture-induced healing in rabbits. Medscape Gen. Med. 2007, 9, 23.

17. OECD, O. Guide Lines for the Testing of Chemicals/Section 4: Health Effects Test No 423: Acute oral Toxicity-Acute Toxic Class Method; OECD: Paris, France, 2002.

18. Balgoon, M.J. Assessment of the Protective Effect of Lepidium sativum against Aluminum-Induced Liver and Kidney Effects in Albino Rat. Biomed. Res. Int. 2019, 2019. [CrossRef]

19. Attia, E.S.; Amer, A.H.; Hasanein, M.A. The hypoglycemic and antioxidant activities of garden cress (Lepidium sativum L.) seed on alloxan-induced diabetic male rats. Nat. Prod. Res. 2019, 33, 901-905. [CrossRef]

20. Zhao, X.; Wu, Z.-X.; Zhang, Y.; Yan, Y.-B.; He, Q.; Cao, P.-C.; Lei, W. Anti-osteoporosis activity of Cibotium barometz extract on ovariectomy-induced bone loss in rats. J. Ethnopharmacol. 2011, 137, 1083-1088. [CrossRef] [PubMed]

21. Fayed, H.A.; Barakat, B.M.; Elshaer, S.S.; Abdel-Naim, A.B.; Menze, E.T. Antiosteoporotic activities of isoquercitrin in ovariectomized rats: Role of inhibiting hypoxia inducible factor-1 alpha. Eur. J. Pharmacol. 2019, 865, 172785. [CrossRef]

22. Abdallah, H.M.; Al-Abd, A.M.; Asaad, G.F.; Abdel-Naim, A.B.; El-Halawany, A.M. Isolation of antiosteoporotic compounds from seeds of Sophora japonica. PLoS ONE 2014, 9, e98559. [CrossRef]

23. Farag, M.A.; Ali, S.E.; Hodaya, R.H.; El-Seedi, H.R.; Sultani, H.N.; Laub, A.; Eissa, T.F.; Abou-Zaid, F.O.F.; Wessjohann, L.A. Phytochemical Profiles and Antimicrobial Activities of Allium cepa Red cv. and A. sativum Subjected to Different Drying Methods: A Comparative MS-Based Metabolomics. Molecules 2017, 22, 761. [CrossRef] [PubMed]

24. Farag, M.A.; El-Kersh, D.M.; Ehrlich, A.; Choucry, M.A.; El-Seedi, H.; Frolov, A.; Wessjohann, L.A. Variation in Ceratonia siliqua pod metabolome in context of its different geographical origin, ripening stage and roasting process. Food Chem. 2019, 283, 675-687. [CrossRef] [PubMed]

25. Sakna, S.T.; Mocan, A.; Sultani, H.N.; El-Fiky, N.M.; Wessjohann, L.A.; Farag, M.A. Metabolites profiling of Ziziphus leaf taxa via UHPLC/PDA/ESI-MS in relation to their biological activities. Food Chem. 2019, 293, 233-246. [CrossRef] [PubMed] 
26. Farag, M.A.; El-Kersh, D.M.; Rasheed, D.M.; Heiss, A.G. Volatiles distribution in Nigella species (black cumin seeds) and in response to roasting as analyzed via solid-phase microextraction (SPME) coupled to chemometrics. Ind. Crops Prod. 2017, 108, 564-571. [CrossRef]

27. Watts, N.B. Postmenopausal osteoporosis: A clinical review. J. Womens Health 2018, 27, 1093-1096. [CrossRef] [PubMed]

28. Chen, L.; Yang, L.; Yao, M.; Cui, X.-J.; Xue, C.-C.; Wang, Y.-J.; Shu, B. Biomechanical characteristics of osteoporotic fracture healing in ovariectomized rats: A systematic review. PLoS ONE 2016, 11, e0153120. [CrossRef]

29. El, N.K.; Hazzaa, H.; Hemoud, H.; Imam, O. Clinical and Radiographic Assessment of Single or Combined Treatment with Lepidium sativum and Alendronate of Non-Surgically Treated Chronic Periodontitis in Postmenopausal Osteoporotic Women. J. Int. Acad. Periodontol. 2019, 21, 20-28.

30. Minkin, C. Bone acid phosphatase: Tartrate-resistant acid phosphatase as a marker of osteoclast function. Calcif. Tissue Int. 1982, 34, 285-290. [CrossRef]

31. Selek, S.; Koyuncu, I.; Caglar, H.G.; Bektas, I.; Yilmaz, M.A.; Gonel, A.; Akyuz, E. The evaluation of antioxidant and anticancer effects of Lepidium Sativum Subsp Spinescens L. methanol extract on cancer cells. Cell. Mol. Biol. 2018, 64, 72-80. [CrossRef]

32. Smolinska, B.; Szczodrowska, A. Antioxidative response of Lepidium sativum L. during assisted phytoremediation of Hg contaminated soil. New Biotech. 2017, 38, 74-83. [CrossRef] [PubMed]

33. Al-Sheddi, E.S.; Farshori, N.N.; Al-Oqail, M.M.; Musarrat, J.; Al-Khedhairy, A.A.; Siddiqui, M.A. Protective effect of Lepidium sativum seed extract against hydrogen peroxide-induced cytotoxicity and oxidative stress in human liver cells (HepG2). Pharm. Biol. 2016, 54, 314-321. [CrossRef] [PubMed]

34. Zhou, Q.; Zhu, L.; Zhang, D.; Li, N.; Li, Q.; Dai, P.; Mao, Y.; Li, X.; Ma, J.; Huang, S. Oxidative stress-related biomarkers in postmenopausal osteoporosis: A systematic review and meta-analyses. Dis. Markers 2016, 2016. [CrossRef] [PubMed]

35. Bonaccorsi, G.; Piva, I.; Greco, P.; Cervellati, C. Oxidative stress as a possible pathogenic cofactor of post-menopausal osteoporosis: Existing evidence in support of the axis oestrogen deficiency-redox imbalance-bone loss. Indian J. Med. Res. 2018, 147, 341.

36. Manolagas, S.C. From estrogen-centric to aging and oxidative stress: A revised perspective of the pathogenesis of osteoporosis. Endocr. Rev. 2010, 31, 266-300. [CrossRef]

37. Altindag, O.; Erel, O.; Soran, N.; Celik, H.; Selek, S. Total oxidative/anti-oxidative status and relation to bone mineral density in osteoporosis. Rheumatol. Int. 2008, 28, 317-321. [CrossRef]

38. Domazetovic, V.; Marcucci, G.; Iantomasi, T.; Brandi, M.L.; Vincenzini, M.T. Oxidative stress in bone remodeling: Role of antioxidants. Clin. Cases Miner. Bone Metab. 2017, 14, 209. [CrossRef] [PubMed]

39. Bai, X.-C.; Lu, D.; Liu, A.-L.; Zhang, Z.-M.; Li, X.-M.; Zou, Z.-P.; Zeng, W.-S.; Cheng, B.-L.; Luo, S.-Q. Reactive oxygen species stimulates receptor activator of NF- $\kappa B$ ligand expression in osteoblast. J. Biol. Chem. 2005, 280, 17497-17506. [CrossRef]

40. Zhang, J.-K.; Yang, L.; Meng, G.-L.; Fan, J.; Chen, J.-Z.; He, Q.-Z.; Chen, S.; Fan, J.-Z.; Luo, Z.-J.; Liu, J. Protective effect of tetrahydroxystilbene glucoside against hydrogen peroxide-induced dysfunction and oxidative stress in osteoblastic MC3T3-E1 cells. Eur. J. Pharmacol. 2012, 689, 31-37. [CrossRef]

41. Martin, T.J. Historically significant events in the discovery of RANK/RANKL/OPG. World J. Orthop. 2013, 4, 186. [CrossRef]

42. Azizieh, F.Y.; Shehab, D.; Jarallah, K.A.; Gupta, R.; Raghupathy, R. Circulatory Levels of RANKL, OPG, and Oxidative Stress Markers in Postmenopausal Women With Normal or Low Bone Mineral Density. Biomark. Insights 2019, 14, 1177271919843825. [CrossRef] [PubMed]

43. Imade, O.V.; Erinfolami, W.A.; Ajadi, R.A.; Abioja, M.O.; Rahman, S.A.; Smith, O.F.; Gazal, O.S. Effects of Lepidium sativum supplementation on growth and gonadotropins secretion in ovariectomized, estrogen-implanted rabbits. Asian Pac. J. Reprod. 2018, 7, 155. [CrossRef]

44. Ghante, M.H.; Badole, S.L.; Bodhankar, S.L. Health benefits of garden cress (Lepidium sativum Linn.) seed extracts. InNuts and seeds in health and disease prevention. Academic Press. 2011, 521-525. [CrossRef]

45. Oszmianski, J.; Kolniak-Ostek, J.; Wojdylo, A. Application of ultra performance liquid chromatography-photodiode detector-quadrupole/time of flight-mass spectrometry (UPLC-PDA-Q/TOF-MS) method for the characterization of phenolic compounds of Lepidium sativum L. sprouts. Eur. Food Res. Technol. 2013, 236, 699-706. [CrossRef] 
46. Piacente, S.; Carbone, V.; Plaza, A.; Zampelli, A.; Pizza, C. Investigation of the tuber constituents of maca (Lepidium meyenii Walp.). J. Agric. Food Chem. 2002, 50, 5621-5625. [CrossRef]

47. Sansom, C.E.; Jones, V.S.; Joyce, N.I.; Smallfield, B.M.; Perry, N.B.; van Klink, J.W. Flavor, glucosinolates, and isothiocyanates of Nau (Cook's scurvy grass, Lepidium oleraceum) and other rare New Zealand Lepidium species. J. Agric. Food Chem. 2015, 63, 1833-1838. [CrossRef]

48. Wang, J.; Yu, H.; Zhao, Z.; Sheng, X.; Shen, Y.; Gu, H. Natural Variation of Glucosinolates and Their Breakdown Products in Broccoli (Brassica oleracea var. italica) Seeds. J. Agric. Food Chem. 2019, 67, 12528-12537. [CrossRef]

49. Wang, S.; Shi, P.; Qu, L.; Ruan, J.; Yang, S.; Yu, H.; Zhang, Y.; Wang, T. Bioactive constituents obtained from the seeds of Lepidium apetalum Willd. Molecules 2017, 22, 540. [CrossRef]

50. Hijazin, T.; Radwan, A.; Abouzeid, S.; Dräger, G.; Selmar, D. Uptake and modification of umbelliferone by various seedlings. Phytochemistry 2019, 157, 194-199. [CrossRef]

51. Alqahtani, F.Y.; Aleanizy, F.S.; Mahmoud, A.Z.; Farshori, N.N.; Alfaraj, R.; Al-Sheddi, E.S.; Alsarra, I.A. Chemical composition and antimicrobial, antioxidant, and anti-inflammatory activities of Lepidium sativum seed oil. Saudi J. Biol. Sci. 2019, 26, 1089-1092. [CrossRef]

52. Kerwin, J.L.; Torvik, J.J. Identification of monohydroxy fatty acids by electrospray mass spectrometry and tandem mass spectrometry. J. Anal. Biochem. 1996, 237, 56-64. [CrossRef] [PubMed]

53. Martin-Arjol, I.; Bassas-Galia, M.; Bermudo, E.; Garcia, F.; Manresa, A. Identification of oxylipins with antifungal activity by LC-MS/MS from the supernatant of Pseudomonas 42A2. Chem. Phys. Lipids 2010, 163, 341-346. [CrossRef] [PubMed]

54. Jeong, J.; Park, H.; Hyun, H.; Kim, J.; Kim, H.; Oh, H.I.; Hwang, H.S.; Kim, D.K.; Kim, H.H. Effects of Glucosinolates from Turnip (Brassica rapa L.) Root on Bone Formation by Human Osteoblast-Like MG-63 Cells and in Normal Young Rats. Phytother. Res. 2015, 29, 902-909. [CrossRef]

55. Folwarczna, J.; Zych, M.; Burczyk, J.; Trzeciak, H.; Trzeciak, H.I. Effects of natural phenolic acids on the skeletal system of ovariectomized rats. Planta Med. 2009, 75, 1567-1572. [CrossRef]

56. Zhao, X.-L.; Chen, L.-F.; Wang, Z. Aesculin modulates bone metabolism by suppressing receptor activator of NF- $\mathrm{BB}$ ligand (RANKL)-induced osteoclastogenesis and transduction signals. Biochem. Biophys. Res. Commun. 2017, 488, 15-21. [CrossRef] [PubMed]

57. Vanek, C.; Connor, W.E. Do n-3 Fatty Acids Prevent Osteoporosis? Oxford University Press: Oxford, UK, 2007.

58. Van Papendorp, D.; Coetzer, H.; Kruger, M. Biochemical profile of osteoporotic patients on essential fatty acid supplementation. Nutr. Res. 1995, 15, 325-334. [CrossRef]

59. Pankova, S.; Tsvetkova, D. Role of phytoestrogens in prevention of osteoporosis. Int. J. Curr. Pharm. Res. 2015, 7, 1-6. 